\title{
Exploring Thai EFL Students' Knowledge of English Binomials
}

\author{
Sichabhat Boonnoon ${ }^{1}$ \\ ${ }^{1}$ Faculty of Liberal Arts and Management Science, Kasetsart University, Thailand \\ Correspondence: Sibhabhat Boonnoon, Faculty of Liberal Arts and Management Science, Kasetsart University, \\ 59 Moo 1, Chiangkhrua, Sakon Nakhon, Thailand.
}

Received: December 23, 2019

Accepted: January 15, 2020

Online Published: January 16, 2020

doi: 10.5539/elt.v13n2p48

URL: https://doi.org/10.5539/elt.v13n2p48

\begin{abstract}
One sub-type of collocations which is under-researched is binomials. The purposes of this study were to investigate Thai EFL students' knowledge of English binomials, determine the syntactic structure of the internal elements of binomials reported as most or least known by them, and test if the students' knowledge of binomials was significantly different when taking account of their years of study. The sample was 130 first - sixth year students enrolled in four different faculties at a university in northeastern Thailand, and classified as intermediate EFL learners for the purpose of this study through the online Oxford Placement Test. An acceptability judgment test of English binomials was used to collect the data. The results revealed that, on the whole, the participants had a low level of knowledge of English binomials; there was no significant difference in their knowledge regarding the syntactic structure of binomials (Noun+Noun and Verb+Verb); and the participants were not significantly different in their knowledge in terms of their years of study. The results pertaining to the participants' low level of knowledge of binomials were discussed in relation to lack of exposure to English and effective pedagogy of English idioms.
\end{abstract}

Keywords: binomials, Thai EFL students, knowledge

\section{Statement of the Problem}

In the literature research abounds regarding EFL/ESL learners' competence in English idiomatic expressions (e.g. Almashikhi, 2018; Tran, 2013) and collocations in particular (e.g. Dokchandra, 2015, 2019; Mongkolchai, 2009; Talakoob \& Koosha, 2017), but the studies on EFL learners' knowledge or competence in the English expressions focusing on binomials as one type of collocations are scant. In the context of Thailand where English has been taught as a foreign language in almost every educational settings and at nearly all levels, research on English binomials is even more difficult to find. Most research has been conducted to explore Thai EFL tertiary learners' holistic knowledge of collocations (Maneewan, 2017; Pisitsenaku, 2019; Wasuntarasophit, 2015) and the learners' knowledge of collocations at the receptive and productive levels (e.g. Detdamrongpreecha, 2014; Dokchandra, 2019). Despite the fact that binomials are one essential part of English idiomatic expressions, they are under-researched. To attain more body of knowledge on how EFL learners perform in regard to the English binomials especially the ones that are most commonly used would add to the richness of literature in this area.

\section{Significance of the Study}

It is hoped that the current study will be of value to EFL teachers as well as syllabus designers because binomials are indispensable for effective English use on a daily basis, especially the spoken English. With sufficient knowledge of commonly used English binomials which are referred to as fixed expressions (Lewis, 2000), learners will reap invaluable benefits both in terms of fluent use of the language and impressive performance as the takers of a standardized English test. The following excerpts indicate this point of view:

The role of fixed expressions in language has become an important focus of study in linguistics, particularly in light of the idiom principle proposed by Sinclair (1991), which implied that a large part of the language we produce is pre-patterned and formulaic (Kopaczy \& Sauer, 2014).

Binomials, as a type of lexical collocations, are important since they make spoken and written language stimulating and interesting. Using collocations may make EFL learners sound more native-like, that is, their speech will be less literal and monotone. The mastery of such expressions may enhance the learners' oral and written skills in the target language; thus, their importance. (Alotaibi \& Alotaibi (2015) 


\section{Literature Review}

\subsection{Collocation Defined}

The term collocation has been defined in various but seemingly similar ways. According to McCarthy and O'Dell (2005), collocation is a close word in combination with other words as in the following examples: too collocates with much or late; the word tall seems to collocate with building and high with mountain. Lewis (2000) defines collocation as the method of unexpected natural co-occurrence with lexical items in a context. Oxford Collocations Dictionary for Students of English (Oxford University Press, 2009) clearly defines collocation as "the way words combine in a language to produce natural-sounding speech and writing (p. v). Strong wind, and heavy rain are provided as an elaboration in this regard.

\subsection{Importance of Collocation Knowledge}

The importance of knowledge of collocations has been highlighted for language competence in three broad aspects. First, acquisition of language knowledge is impossible without collocation knowledge. Collocations are abundantly found everywhere (Hill, 2000), and they account for up to $70 \%$ of everything in the English language. Moreover, Nation (2001) posits that the most important thing is that language knowledge is nothing but collocation knowledge since learned formulaic sequences of words are the basics of learning, knowledge, and use. Knowledge of collocations is also vital because it is key to native-like production (Men, 2018).

A strong collocation knowledge helps to achieve the native-like production through promoting fluency. The difference between native speakers and non-native speakers is that the former have accumulated more examples of the language and are able to speak quite fast because of their drawing on a tremendous amount of ready-made language in their long-term memory (Hill, 2000). L2 learners' native-like fluency is showcased through their proficient use of language. It is normal for L2 learners to compose sentences by putting words together while communicating in the target language, and their speech is hindered by this process. A bit longer time is spent by some English learners to think of appropriate words to say when speaking, and this consequently results in their broken English because of the arbitrary word choice. However, with collocation knowledge, they will speak faster as a result of their collocations stored in their long-term memory that works automatically, hence no waste of processing time.

Additionally, collocation knowledge contributes to efficient comprehension for L2 learners. With good collocation knowledge, learners can comprehend text without having to focus on every single word (Hunston \& Francis, 2000). This knowledge can also enhance fluency in reading and listening. L2 learners can reconstruct the meanings though they cannot hear every single word in the speech. Therefore, Lewis (2000) stresses that collocation is the most powerful force for creating and understanding all naturally-occurring texts.

\subsection{Four Broad Aspects of Collocations}

According to Yang and Hendricks (2004), collocations can be noticed through their 4 salient characteristics. First, collocations are a frequent co-occurrence of words between which no new word can be inserted. For example, the phrase bread and butter cannot be inserted with one more word like bread, sugar and butter. Next, within a collocation, a collocate cannot be replaced by a synonym or equivalent word. Business trip, for example, is more acceptable than business journey because journey does not collocate with business. Thirdly, collocations are fixed binomials (James, 1998), like the following phrases: bed and breakfast, more or less, and born and bred. Putting the parts the other way round is impossible. Finally, a high degree of predictability (Hill, 2000) is a salient feature of collocations. For example, when an English native-speaker hears "high and....", s/he will instantly predict that the next word will definitely be "low" as a result of their being familiar with the phrase "high and low" which is frequently used in daily English.

\subsection{Binomials as One Type of Collocations}

Binomials which, according to McCarthy and O'Dell (2001), are two words joined with a conjunction and their order is not possible to change are one type of collocations. For instance, the binomial head or tail cannot be changed to tail or head.

This static feature is referred to as grammatically fossilized collocations by Nation (2001). Binomials do not allow any change to the form of the collocation through a change in word order, for example by and large, law and order or through grammatical change with inflections or part of speech.

\subsection{Past Empirical Research on Collocations and Binomials in Particular}

As mentioned earlier, there is scant research in the literature in regard to binomials both in the context of EFL and ESL learners. Extensive research has been conducted to investigate the English learners' knowledge of 
lexical collocations (e.g. Begagic, 2014; Ei-Dakhs, 2015; Talakoob \& Koosha, 2017) and a combination of grammatical and lexical collocations (e.g. Alsakran, 2011; Bagci, 2014; Banboua, 2016). Holistically, it seems fairly conclusive that the learners' collocation knowledge is poor to moderate at both the receptive and productive levels (Abdullah, Ghani, \& See, 2015; Torabian, Moaros \& Subakir, 2014; Yumanee \& Phoocharoensil, 2013).

Many studies singled out some specific sub-categories of collocations when assessing the learners' collocation knowledge. Focusing on the lexical collocation, some researchers (e.g. Alsakran, 2011; Begagic, 2014; Bueraheng, 2014) determined which type of lexical collocations (verb + noun or adjective + noun) poses more difficulty to the learners. Others focused on the noun + noun category (Boudribila, 2018; Detdamrongprecha, 2014) and the verb + adverb category (Alziabi, 2017). However, many other researchers targeted the grammatical collocations when investigating the learners' knowledge. For example, Alsulayyi (2014) investigated the production of English grammatical collocations by Saudi students in the KSA and the UK. The essays written by the students were analyzed for grammatical collocation errors, and the results revealed that the most common errors made by the students were the noun + preposition and adjective + preposition. Other sub-categories of grammatical collocations such as adjective + that clause and noun + that clause were also found among the errors.

Likewise, some researchers singled out particular sub-categories of grammatical collocations in their studies. Pisitsenakul (2019), focusing on the noun + preposition, preposition + noun, and adjective + preposition collocations, investigated 300 Thai EFL undergraduate students' collocation knowledge and their attitudes towards collocation learning. Based on Benson et al (2010)'s classification of grammatical collocations, Farrokh and Mahmoodzadeh (2012) studied Iranian EFL learners' knowledge of three types of collocations of gerund: verb $+v$-ing, verb (trans) + object $+\mathrm{v}$-ing, and verb (trans) + poss + gerund. They found that the students (high proficiency and low proficiency groups) showcased poor knowledge of grammatical collocations in the sub-type of verb + object + v-ing and verb + poss + gerund. The students' low level of the knowledge was attributed to limited exposure to the target language and lack of systematic teaching of collocations.

Only a small number of studies are found in the literature pertaining to the English learners' competence in binomials, which are included in the lexical collocations. Alotaibi and Alotaibi (2015) investigated the Kuwaiti EFL students' knowledge of binomials, using an acceptability judgment task. The researchers wanted to know if the English proficiency levels of the participants (advanced and intermediate EFL learners) and the syntactic category of binomials play a role in their acquisition of binomials. It was found that the participants (at both advanced and intermediate proficiency levels) were not significantly different in their knowledge of binomials, hence the researchers' conclusion that the participants had little awareness of English binomials. In a large-scale study involving 100 EFL students at a university in Jordan, Hamdan (2005) using a written task, explored how two different proficiency level groups of Jordanian EFL learners interacted with a set of binomials frequently used in everyday language and appear here and there in their ELT materials. The subjects were divided into group one comprising 50 first-year English major students and group two comprising 50 fourth-year English major students. The students in group two were deemed possessing higher proficiency in English than the ones in group one. The overall results were that the participants' general performance in binomials was poor, consolidating previous research about the difficult nature of collocations for EFL learners. Alotaibi and Alotaibi (2015) tested the Kuwaiti EFL students' awareness of binomials to determine if the participants' English proficiency level and the syntactic category of the internal elements of binomials affect their acquisition. On the whole, it was found that the advanced group of the participants performed better than the intermediate group on an acceptability judgment test of binomials, but the difference was not enough to be significant. Also, it was found that the syntactic category of binomial elements (i.e. noun + noun and verb + verb) did not have an impact on their answers.

More recently, Morita \& Wylie (2016) investigated Japanese students' productive knowledge of English binomials and the strategies they employed to produce the binomials when in doubt. The participants, 103 intermediate EFL Japanese students, were administered an online binomial test and a questionnaire. In the test which comprised 40 items, the participants were asked to fill up the second part of the binomial they thought they knew. For example, the binomial "heaven and earth" was presented as "heaven and ". The participants had to figure out what the missing part was, but if they did not know, they were to type ? in the answer box. The results revealed that the participants had productive knowledge of 20 binomials (45.5\%) out of 44 , with $75 \%$ of accuracy rates. Many produced incorrect binomials, drawing on guessing and knowledge of semantic relationship.

The above-mentioned literature seems to conclude that binomials as one type of lexical collocations are difficult 
alike for EFL learners, but no research has been conducted to investigate to what extent Thai EFL students know English binomials. Based on this gap, the following research questions were addressed in this study:

1. To what extent do Thai university EFL students know English binomials?

2. Which syntactic structure of binomials, noun + noun and verb + verb, do the students know better?

3. Is there a significant difference in the knowledge of binomials among the students in their different years of study?

\section{Method}

\subsection{Participants}

The participants in this study consisted of 130 students enrolled in 4 academic faculties in the northeastern campus of Kasetsart University, Thailand. Their mean age was 21 years and most of them $(87 / 66.9 \%)$ were female. In terms of the year of study, most of them (60/46.2\%) were in their third year, followed by fourth year $(38 / 29.2 \%)$, second year (28/21.5\%), and four students each were in their fifth and sixth years respectively. The participants were purposively selected from 240 students of six classes of 40 students, enrolled in Foundation English III, a required course on offer at the campus. A print-out of Oxford English Placement Test (totaling 30 items) was used to classify the students into advanced (with 21-30 scores), intermediate (with 11-20 scores), and elementary (with 0-10 scores) proficiency groups. Finally, 130 intermediate students were chosen as the participants. The rest of the students (110) were not recruited for they were at the elementary level. According to Lewis (2000), EFL students with low proficiency level would pass a test on idiomatic expressions. None of the students was classified as advanced proficiency learners.

\subsection{Data Collection Instrument and Procedure}

An acceptability judgment test of English binomials adapted from Alotaibi and Alotaibi (2015) and Yamashita and Jiang (2012) was used as the tool for collecting the data in this study. This type of test is popularly used because it can well elicit the results of the study as expected by the researcher who can consequently conclude the study results in the most precise and logical manner. In addition, an acceptability judgment test is appropriate for using binomials in a reverse order may not be deemed as grammatically wrong, but as unacceptable. In the test, the participants were asked to read 40 sentences. Of the 40 sentences, twenty sentences contained 20 binomials correctly used (e.g. bread and butter, and other 20 sentences with binomials in reverse order (e.g. butter and bread). Then, they were asked to put a check $(\checkmark)$ after a statement they thought acceptable, and a cross (x) for the one they thought unacceptable as illustrated in Table 1 below. It took approximately 15 minutes for the participants to finish off the test. Both noun + noun and verb + verb binomials were used in this study as in Table 2 below.

Table 1. An example of a binomial used in each statement

\begin{tabular}{cc|c}
\hline No. & \multicolumn{1}{c|}{ Statement } & Acceptable / Unacceptable \\
\hline 001 & We need to consider the pros and cons of each measure. & $\checkmark$ \\
002 & The cons and pros of the measure must be considered. & $\mathrm{x}$ \\
\hline
\end{tabular}

Table 2. Binomials of two syntactic structures used in the study

\begin{tabular}{cc}
\hline Noun + Noun binomials & Verb + Verb binomials \\
\hline pros and cons & give and take \\
man and wife & toss and turn \\
salt and pepper & win or lose \\
bread and butter & rise and shine \\
tooth and nail & crash and burn \\
facts and figures & hit and run \\
life and death & hide and seek \\
fish and chips & buy and sell \\
flesh and blood & rock and roll \\
soap and water & open and shut
\end{tabular}


This shortlist of binomials was chosen from previous studies (Alotaibi \& Alotaibi, 2015; Morita et al., 2014) and on the basis of their frequency in the Corpus of Contemporary American English (COCA). For instance, life and death was mentioned 1940 times while buy and sell was mentioned 504 times, the former as a Noun+Noun binomial indicating its being more frequent than the latter as a Verb+Verb binomial which is less frequent. The researcher drew on Cambridge Dictionary Online for the sentences containing the target binomials. For the intentional reversely-ordered binomials, the researcher merely changed the normal order of the phrases (e.g. bread and butter to butter and bread) in order to mean them as distractors.

The researcher piloted the first draft of the test with a group of 10 students undertaking Introduction to English Reading and Writing Skills, a core course for first year students of English at the campus. Clarity, reliability and validity of the piloted instrument were checked, and some modifications were made pertaining to the comments and feedback provided by three experts in the field of English studies and related disciplines. With the informed consent of the participants to participate in the study, the finalized version of the test was administered during the second term of the academic year 2018 at the campus. The reliability co-efficient of the test was .81 indicating that the test was appropriate for use in the present study.

\subsection{Data Analysis}

The data was analyzed in the software package programme IBM SPSS (Statistical Package for Social Sciences) Statistics 22. Independent t-test, one-way ANOVA, and the Tukey HSD test were used in the evaluation of the data. The one-way ANOVA can be used for the case of a quantitative outcome with a categorical explanatory variable that has two or more levels of treatment (Seltman 2014). The Tukey test was applied as variances were homogeneous and the data number was low.

\section{Results and Discussion}

On the whole, as shown in Table 3, the participants' knowledge of English binomials was as at a low level.

Table 3. Mean and standard deviation of the participants' binomial knowledge $(\mathrm{n}=130)$

\begin{tabular}{ccccc}
\hline Minimum & Maximum & Mean & S.D. & Meaning \\
\hline 11 & 23 & 17.91 & 2.45 & Low \\
\hline
\end{tabular}

Out of 40 total scores on the English binomial test, the average score obtained by the participants was only 17.91 (44.77\%), which was below half of the total score.

The findings pertaining to the syntactic structures of binomials revealed that the participants performed slightly better on the Noun + Noun binomials than on the Verb + Verb ones as indicated in Table 4.

Table 4. Mean and percentage of the participants' knowledge of binomials by syntactic structures $(n=130)$

\begin{tabular}{ccc}
\hline Binomial structure & Mean & Percent \\
\hline Noun + Noun binomials & 9.36 & $45 \%$ \\
Verb + Verb binomials & 9.38 & $47 \%$ \\
Overall & $\mathbf{9 . 3 7}$ & $\mathbf{4 6 \%}$
\end{tabular}

The result of the $t$-test revealed that there was no significant difference $(t=0.82, \mathrm{df}=129$, sig. $=.935)$ between the two means of both binomial structures (noun + noun and verb + verb), indicating that the participants were almost equal in terms of their knowledge in the English binomials according to their syntactic structures. Details of the correct answers to each item on the test can be consulted in Table 5 below. 
Table 5. Accuracy rates on the correct answers on the test of English binomials

\begin{tabular}{cc}
\hline Noun + Noun Binomials & Correct rates \\
\hline Pros and cons & $64 \%$ \\
Man and wife & $41 \%$ \\
Salt and pepper & $38 \%$ \\
Tooth and nail & $42 \%$ \\
Facts and figures & $70 \%$ \\
Bread and butter & $49 \%$ \\
Flesh and blood & $32 \%$ \\
Soap and water & $32 \%$ \\
Life and death & $42 \%$ \\
Fish and chips & $32 \%$ \\
\hline Verb + Verb Binomials & \\
\hline Rise and shine & $37 \%$ \\
Toss and turn & $39 \%$ \\
Buy and sell & $58 \%$ \\
Hit and run & $66 \%$ \\
Hide and seek & $66 \%$ \\
Give and take & $47 \%$ \\
Open and shut & $38 \%$ \\
Win or lose & $36 \%$ \\
Crash and burn & $36 \%$ \\
Rock and roll & $45 \%$ \\
\hline
\end{tabular}

Regarding the Noun + Noun binomials, it can be clearly seen that there were only two items that the students could answer with higher than 50 percent of accuracy, item 1 (pros and cons), and item 12 (facts and figures). The accuracy rate of the rest of the items was lower than 50 percent. In the same vein, the students' accuracy rates for the test items of Verb + Verb binomials were lower than 50 percent. Only 3 items gained higher than 50 percent of accuracy rate and these were item 18 (buy and sell), item 20 (hit and run), and item 24 (hide and seek).

As for the correct answer on facts and figures (70\%) and pros and cons $(64 \%)$, it could be explained that these two binomials might have been familiar with the students because they appear in the coursebooks (New Interchange series) used for foundation English courses at this campus. Therefore, it would sound strange or awkward for the students if these binomials are in reverse order. The similar explanation could be provided for the high accuracy rates of the Verb + Verb binomials hit and run, hide and seek, and buy and sell. Especially the phrase buy and sell has a Thai equivalent (ซื้อขาย) which might help the students in determining the correct English equivalent.

A one-way analysis of variance (ANOVA) was computed to test for differences among the participants enrolled in different years of study pertaining to their knowledge of the English binomials.

Table 6. F-test results for the knowledge of binomials by year of study $(n=130)$

\begin{tabular}{lccccc}
\hline & $S S$ & $d f$ & $M S$ & $F$ & Sig. \\
\hline Between groups & 27.134 & 4 & 6.783 & 1.192 & .318 \\
Within groups & 711.489 & 125 & 5.692 & & \\
$\quad$ Total & 738.623 & 129 & & & \\
\hline
\end{tabular}


As indicated in Table 6, the P-value (Sig. $=.318)$ is larger than the alpha value $(0.05)$. It was therefore concluded that the students enrolled in different study years were not significantly different with regard to their knowledge of English binomials.

The findings here were consistent with other studies (Alotaibi \& Alotaibi, 2015; Basim, 2009; Morita \& Wylie, 2016) which revealed that EFL learners, at the advanced and intermediate proficiency levels, demonstrated low competence in English binomials, indicating that English idiomatic expressions pose difficulty for non-native English speakers (2008). This result may be attributed to the fact that the students lack experience with English outside the classroom whether in the form of reading, watching TV or videos such as the ones on YouTube. Though the teacher may spontaneously use chunks, not necessarily in the form of binomials, in the course of the instruction in class, the students may not learn those chunks because acquiring them is a slow process (Laufer, 2010). Thus, in order to help the learners acquire binomials, there is a need to supplement them with classroom instruction as suggested by Szudarski (2012).

\section{Conclusion and Recommendations}

The current study was conducted to explore the level of Thai university EFL students' knowledge of English binomials and the internal syntactic structures of the binomials as well as determine if their year of study had a significant correlation with their knowledge. It was found that, on the whole, the participants had a low level of English binomials. It could not be claimed that the participants knew one syntactic structure of binomials better than the other; that is the Noun + Noun and the Verb + Verb binomials because the scores gained from the test regarding each syntactic structure was almost equal. Additionally, the results revealed no significant difference in regard to the participants' year of study and their knowledge of English binomials.

Based on the results of this study, the following recommendations are offered: First, to enhance the EFL learners' exposure to language, especially English binomials as one type of collocations, explicit instruction of binomials, those that are commonly used in particular, should be embedded in every English courses on offer at university. English teachers should also opt to use instructional materials such as a coursebook in which idiomatic expressions including binomials are an integrant part so that the learners are given an opportunity to get exposed to more English idiomatic expressions. For further studies, replication of this study could be implemented but in a broader context where EFL tertiary students of medium or high proficiency levels at a national level are investigated for their knowledge of English binomials. Further research could also be designed to study the effect of a particular teaching method such as explicit instruction on the enhancement of EFL learners' competence in English binomials. Last but not least, an observation study could be carried out to explore the behaviours towards using English idiomatic expressions, particularly binomials, by English teachers at a university level in order that more light could be shed on this line of research.

\section{References}

Abdullah, A., Ghani, R.A. \& See, Soo-Yin. (2015). The knowledge of lexical collocation among university students and its relation to their speaking proficiency. International Letters of Social and Humanities Sciences, 61, 7-16. https://doi.org/10.18052/www.scipress.com/ILSHS.61.7

Almashikhi, K. (2018). Omani EFL learners' proficiency in using idiomatic expressions: Researched pedagogical perspectives. Journal of Literature, Languages, and Linguistics, 51, 21-40.

Alotaibi, A.M. \& Alotaibi, M.A. (2015). The acquisition of binomials by Kuwaiti EFL learners. International Journal of English Linguistics, 5(3), 63-71. http://dx.doi.org/10.5539/ijel.v5n3p63

Alsulayyi, M.N. (2014). The use of grammatical collocations by advanced Saudi EFL learners in the UK and KSA. International Journal of English Linguistics, 5(1), 32-43. http://dx.doi.org/10.5539/ijel.v5n1p32

Alziabi, S.E. (2017). Guessing verb + adverb collocations: Arab EFL learners' use of electronic dictionaries. Lexikos, 27, 50-77. https://doi.org/10.5788/27-1-1394

Bagci, N.D. (2014). Turkish university level EFL learners' collocational knowledge at receptive and productive levels (Unpublished master's thesis). Middle East Technical University.

Banboua, N.M.S. (2016). Testing collocational knowledge of Yemeni EFL university students at Universiti Utara Malaysia. Arab World English Journal, 7(1), 370-378. http://dx.doi.org/10.2139/ssrn.2804031

Bueraheng, N. \& Laohawiriyanon, C. (2014). Does learners' degree of exposure to English language influence their collocational knowledge? International Journal of English and Literature (IJEL), 4(3), 1-10.

Detdamrongpreecha, B. (2014). The acquisition of basic collocations by Thai learners of English. Susan Dusit University Research Journal, 10(3), 37-53. 
Dokchandra, D. (2015). The effects of collocation noticing instruction on Thai EFL learners' collocational competence. Journal of Advances in English Language Teaching, 3(1), 1-11.

Dokchandra, D. (2019). Thai EFL learners' collocational competence and their perceptions of collocational difficulty. Theory and Practice in Language Studies, 9(7), 776-784. http://dx.doi.org/10.17507/tpls.0907.04

Ei-Dakhs, D.A. (2015). The lexical collocational competence of Arab undergraduate EFL learners. International Journal of English Linguistics, 5(5), 60-74.

Farrokh, P. \& Mahmoodzadh, K. (2012). Iranian learners' knowledge of English grammatical collocations of gerund. Journal of Basic and Applied Scientific Research, 2(11), 11834-11844.

Hamdan, J.M.(2005). Interacting with binomials: Evidence from Jordanian EFL learners. Poznan Studies in Contemporary Linguistics, 40, 135-156.

Hill, J. (2000). Revising priorities: From grammatical failure to collocational success. In M. Lewis (Ed.), Teaching collocations: further developments in the lexical approach (pp.49-60). London: Language Teaching Publications.

Hunston, S. \& Francis, G. (2000). Pattern grammar. A corpus-driven approach to the lexical grammar of English. Amsterdam: Benjamins.

James, C. (1998). Errors in language learning and use: Exploring error analysis. New York: Addison Wesley Longman Limited.

Jasim, B.Y. (2008). Investigating the advanced Iraqi EFL learners' mastery of using English irreversible binomials. Adab Al Rafidayn, 53, 561-591.

Kopaczyk, J. \& Sauer, H. (2014). Exploring binomials: History, structure, motivation and function. Proceedings of the 18th International Conference on English Historical Linguistics (pp.14-18). KU Leuven, Belgium.

Laufer, B. (2010). Form focused instruction in second language vocabulary learning. In R. Chacón-Beltrán, C. Abello-Contesse, M. M. Torreblanca-López and M. D. López- Jiménez (eds.), Further insights into nonnative vocabulary teaching and learning (pp. 15-27). Bristol, Buffalo, Toronto: Multilingual Matters.

Lewis, M. (2000). Teaching collocation: Further developments in the lexical approach. London: Language Teaching Publications.

McCarthy, M. \& O’Dell, F. (2005). English Collocations in Use. New York: Oxford University Press

Maneewan, W. (2017). A study of English collocation competence of Thai EFL learners (Unpublished master's thesis). Thammasat University, Thailand.

Men, H. (2018). Vocabulary increase and collocation learning: A corpus-based cross-sectional study of Chinese learners of English. Singapore: Springer.

Mongkolchai, A. (2009). A study of university students' ability in using English collocations (Unpublished master's thesis). Srinakharinwirot University, Thailand.

Morita, M., Sakaue, T., Murao, R. \& Matsuno K. (2014). Strategies used by Japanese learners of English to determine word order in binomials. ARELE : Annual Review of English Language Education in Japan, 25, 65-78. https://doi.org/10.20581/arele.25.0_65

Morita, M. \& Wylie, J. (2016). Productive Knowledge of English Binomials by Japanese Learners of English. Hiroshima Studies in Language and Language Education, 19, 83-92.

Nation, I.S.P. (2001). Learning vocabulary in another language. Cambridge: Cambridge University Press.

Pisitsenakul, S. (2019). The use of grammatical collocations with prepositions and attitude towards collocations learning of Thai EFL undergraduate students. Rangsit Journal of Educational Studies, 6(1), 51-64. https://doi.org/10.14456/rjes.2019.5

Sinclair, J. (1991). Corpus, concordance and collocation. Oxford: Oxford University Press.

Szudarski, P. (2012). Effects of meaning-and form-focused instruction on the acquisition of verb-noun collocations in L2 English. Journal of Second Language Teaching \& Research, 1(2), 3-37.

Talakoob, F. \& Koosha, M. (2017). Advanced EFL learners' knowledge of different collocation types. Journal of Applied Linguistics and Language Research, 4(2), 267-276.

Talakoob, F. \& Koosha, M. (2017). Productive and receptive collocational knowledge of Iranian EFL learners at different proficiency levels. International Journal of Applied Linguistics \& English Literature, 6(7), 11-16. 
Torabian, A.H., Maros, M. \& Subakir, M.Y.M. (2014). Lexical collocational knowledge of Iranian undergraduate learners: implications for receptive \& productive performance. Procedia-Social and Behavioral Sciences, 158, 343-350. https://doi.org/10.1016/j.sbspro.2014.12.098

Tran, H.Q. (2013). Figurative idiomatic competence: An analysis of EFL learners in Vietnam. Language Education in Asia, 4(1), 23-38. http://dx.doi.org/10.5746/LEiA/13/V4/I1/A3/Tran

Yang, Y. \& Hendricks, A. (2004). Collocation awareness in the writing process. Reflections of English Language Teaching, 51-78.

Wasuntarasophit, S. (2015). Explicit instruction of collocations: An impact on learners' use and perceptions. Journal of Humanities and Social Sciences, 11(2), 37-71.

Yumanee, C. \& Phoocharoensil, S. (2013). Analysis of Collocational Errors of Thai EFL Students. LEARN Journal, 6(1), 88-98.

\section{Copyrights}

Copyright for this article is retained by the author(s), with first publication rights granted to the journal.

This is an open-access article distributed under the terms and conditions of the Creative Commons Attribution license (http://creativecommons.org/licenses/by/4.0/). 